\title{
Aluminum Clad Spent Nuclear Fuel Task 6: Surrogate Sample Preparation and Validation Experiment Test Plan
}

\author{
Michael Connolly
}

July 2018

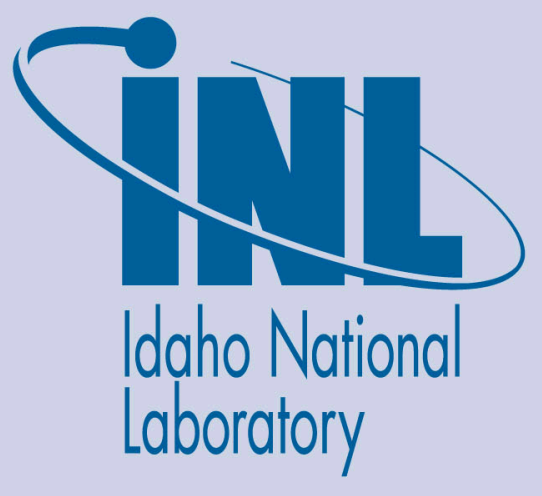

The INL is a U.S. Department of Energy National Laboratory operated by Battelle Energy Alliance 


\section{DISCLAIMER}

This information was prepared as an account of work sponsored by an agency of the U.S. Government. Neither the U.S. Government nor any agency thereof, nor any of their employees, makes any warranty, expressed or implied, or assumes any legal liability or responsibility for the accuracy, completeness, or usefulness, of any information, apparatus, product, or process disclosed, or represents that its use would not infringe privately owned rights. References herein to any specific commercial product, process, or service by trade name, trade mark, manufacturer, or otherwise, does not necessarily constitute or imply its endorsement, recommendation, or favoring by the U.S. Government or any agency thereof. The views and opinions of authors expressed herein do not necessarily state or reflect those of the U.S. Government or any agency thereof. 


\title{
Aluminum Clad Spent Nuclear Fuel Task 6: Surrogate Sample Preparation and Validation Experiment Test Plan
}

\author{
Michael Connolly
}

July 2018

Idaho National Laboratory

Idaho Falls, Idaho 83415

http://www.inl.gov

Prepared for the

U.S. Department of Energy

Office of Environmental Management

Under DOE Idaho Operations Office

Contract DE-AC07-05ID14517 



\section{Aluminum Clad Spent Nuclear Fuel Task 6: Surrogate Sample Preparation and Validation Experiment Test Plan}

INL/EXT-18-45864

July 2018

Prepared by:
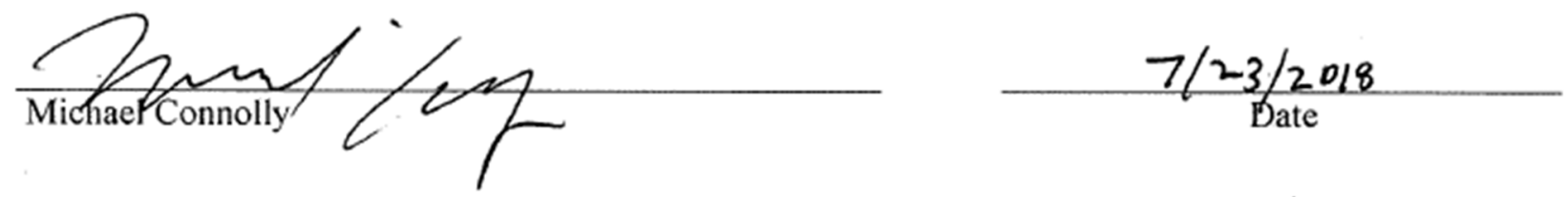

Approved by:
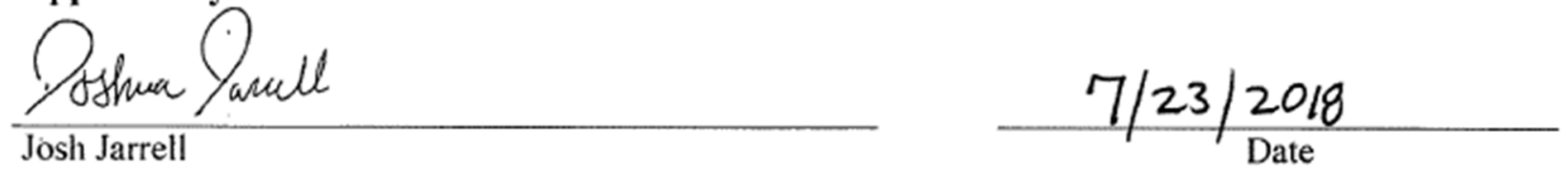

INL Integration Lead
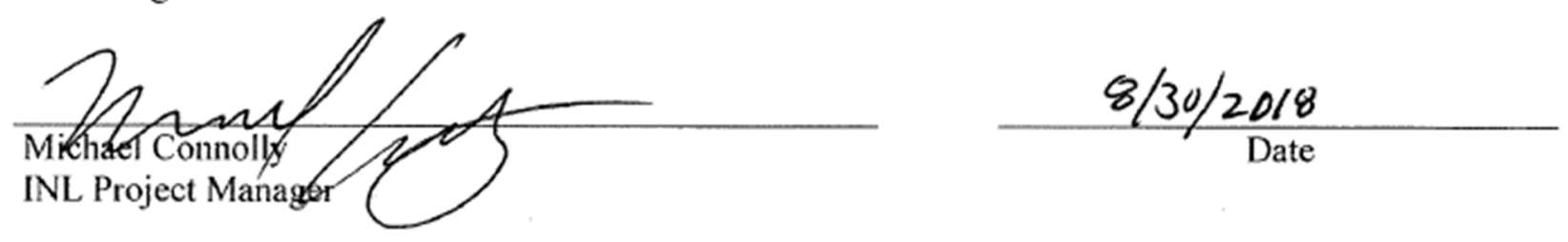



\section{SUMMARY}

This document presents the experimental test plan for Task 6: Surrogate Preparation and Validation. Task 6 will produce and validate surrogate oxyhydroxide materials used in other experimental tasks within the larger Aluminum Clad Spent Nuclear Fuel Long Term Dry Storage Project. Task 6 includes both the preparation and characterization of surrogate oxyhydroxide materials as well as the analysis of oxide/oxyhydroxide layers on Savannah River Site Spent Nuclear Fuel Materials. This test plan provides experimental design details and the task's overall quality assurance approach. 


\section{CONTENTS}

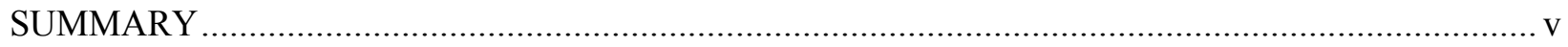

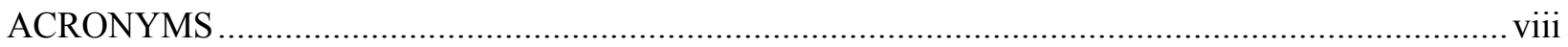

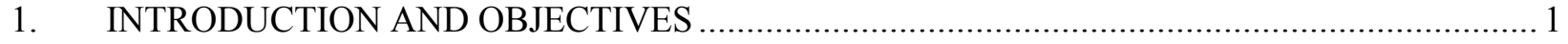

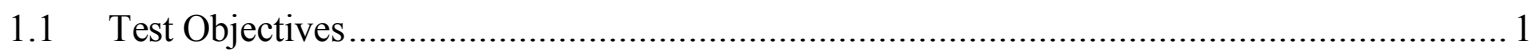

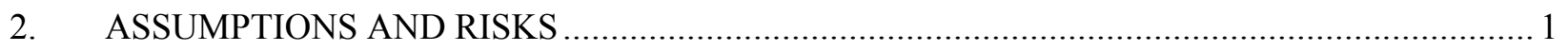

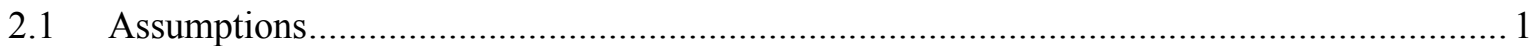

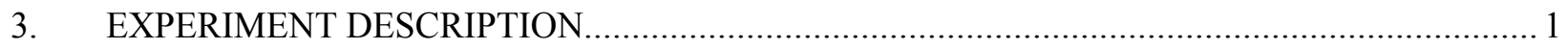

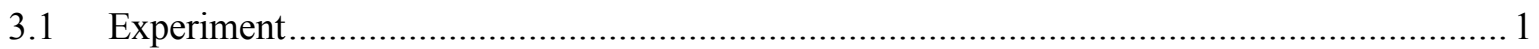

3.1.1 Laboratory Oxyhydroxide Growth ........................................................... 1

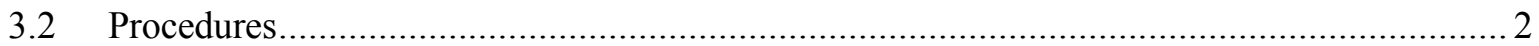

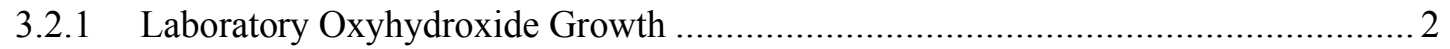

3.2.2 Validation through Characterization of L-Basin ASNF ....................................... 2

3.2.3 Shipment of Samples to INL for Experimental Testing ......................................... 4

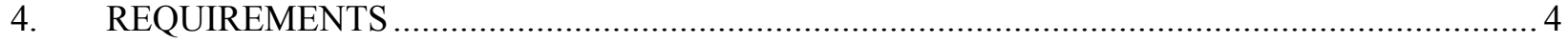

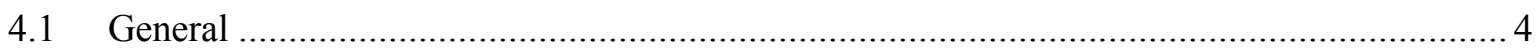

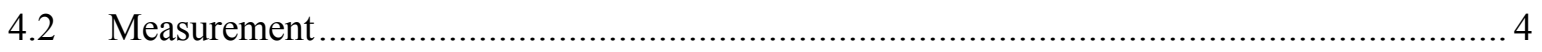

5. ENVIRONMENT, SAFETY, AND HEALTH .............................................................. 4

6. QUALITY ASSURANCE AND DATA/RECORD MANAGEMENT …................................ 5

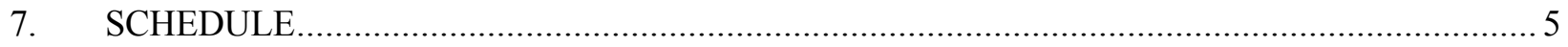

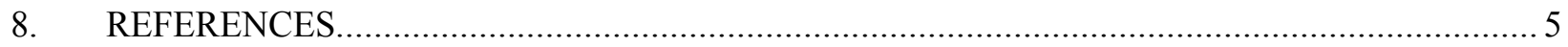

\section{FIGURES}

Figure 1. Hot Wall Water Immersion Corrosion Experimental Setup...................................................2

Figure 2. Plate fuel bundle (right) and debundled fuel plates (left) from Uruguay RU-1 Pool Reactor. 3

\section{TABLES}

Table 1. Task 6 Schedule and Milestones. 5 


\section{ACRONYMS}

ASNF aluminum spent nuclear fuel

DOE Department of Energy

DOE-EM U.S. Department of Energy-Office of Environmental Management

INL Idaho National Laboratory

MURR University of Missouri Research Reactor

SRS Savannah River Site

SRNL Savannah River National Laboratory

SEM scanning electron microscopy

SNF spent nuclear fuel

TTQAP technical task and quality assurance plan

USH Universal Sleeve Housing

XRD $\quad x$-ray diffraction 


\section{Aluminum Clad Spent Nuclear Fuel Task 6: Surrogate Sample Preparation and Validation Experiment Test Plan}

\section{INTRODUCTION AND OBJECTIVES}

\subsection{Test Objectives}

The objective of Task 6 is twofold; prepare oxyhydroxide surrogate samples to be used in other experimental studies within the experimental program and validate the representativeness of surrogate materials by sampling ASNF. Validating that surrogate materials accurately represent aluminum spent nuclear fuel (ASNF) oxyhydroxide layer composition (e.g., gibbsite, bayerite, and boehmite) is critical to ensure results of investigations are representative of actual ASNF [1-3].

\section{ASSUMPTIONS AND RISKS}

\subsection{Assumptions}

The completion of Task 6 activities is contingent upon FY18 funding. This execution plan assumes that FY-18 funds from the U.S. Department of Energy-Office of Environmental Management (DOE-EM) will be provided to Idaho National Laboratory (INL) by June 2018.

ASNF oxyhydroxide sampling activities will require close coordination and integration with Savannah River Site L-Basin operations. It is anticipated that L-Basin can supply ASNF materials to SRNL for characterization in accordance with the schedule outlined within this document.

SRNL will provide laboratory-grown oxyhydroxide materials to INL for subsequent testing in other Task areas within the ASNF Dry Storage Program.

\section{EXPERIMENT DESCRIPTION}

\subsection{Experiment}

\subsubsection{Laboratory Oxyhydroxide Growth}

Oxyhydroxides will be grown on aluminum substrates using a hot wall water immersion method. Following immersion testing, aluminum substrates will be removed, sectioned and oxyhydroxide layers will be characterized using SEM and XRD analysis. Oxyhydroxide growth procedures are summarized below with additional details provided in section 3.2.1:

- Surrogate sample size: $3 \mathrm{~cm}$ and $5 \mathrm{~cm}$ discs

- Anticipated testing time: 1 week to 1 month

- Expected oxide thickness: $1 \mu \mathrm{m}$ to $5 \mu \mathrm{m}$

- Oxyhydroxide compositions: below $70-80^{\circ} \mathrm{C}$, Gibbsite/Bayerite; above $70-80^{\circ} \mathrm{C}$, Boehmite

- Characterization methods: XRD, SEM. 


\subsection{Procedures}

\subsubsection{Laboratory Oxyhydroxide Growth}

Oxyhydroxides will be grown on aluminum substrates using a hot wall water immersion method. In hot wall testing, one surface of a corrosion coupon is heated while the opposite surface is exposed to a bulk solution. This design supplies a heat flux across the sample from one surface to the other and is suitable for replicating conditions in which heat flows in a prescribed direction (e.g. heat transferred to $\mathrm{Al}$ fuel cladding fuel in reactor as well as during spent fuel pool storage due to attendant decay heat).

Aluminum discs (either 3 or $5 \mathrm{~cm}$ in diameter, depending upon experimental setup) of variable alloy composition $(1100,6061$, etc.) will be exposed to a hot wall immersion oxide growth method. (see Figure 1). The discs will be exposed to hot wall immersion testing over a range of water temperatures $\left(50^{\circ} \mathrm{C}\right.$ to $100^{\circ} \mathrm{C}$ ), allowing for the growth of low and high temperature oxyhydroxides (gibbsite and boehmite, respectively) [4]. The duration of tests will range from 1 week to 1 month but will ultimately be dictated by oxide thickness requirements as specified by other experimental studies within the program. Grown oxyhydroxide films are expected to range from 1 to $5 \mu \mathrm{m}$ in thickness.

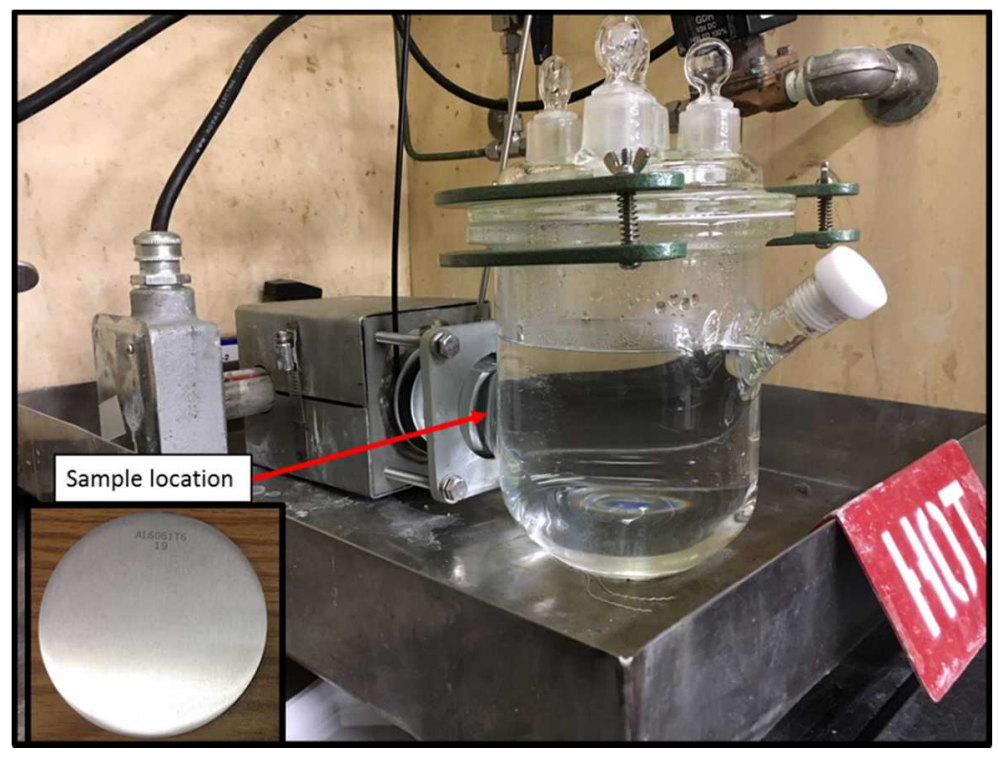

Figure 1. Hot Wall Water Immersion Corrosion Experimental Setup.

Aluminum substrates will be weighed prior to and following hot wall immersion to document oxide weight gain. Subsequent characterization will include XRD, and SEM of the surface and oxide layer cross section. Remaining disc sectioned items will be used for other experimental tasks within the program (e.g. radiolytic gas generation testing, etc.) Initial shakedown testing on aluminum surrogates will include post-immersion storage studies to determine best practices for storage and shipment of oxide films to INL, without comprising (damaging, degrading, or evolving) the oxide layer.

\subsubsection{Validation through Characterization of L-Basin ASNF}

Validation of laboratory-grown oxyhydroxides will be accomplished by comparing material characterization results to the as-grown structure and composition of oxyhydroxides sampled from LBasin ASNF.

Validation activities using FY-17 funding support the characterization and testing of oxides sampled from a Material Test Reactor (MTR) fuel plate from the 50-KW RU-1 pool type reactor in Uruguay. Fuel plates from the RU-1 reactor contain LEU and are clad in Al-1000. Upon discharge, and prior to shipment to Savannah River Site (SRS), the RU-1 fuel plate was stored exposed to ambient air in Uruguay. The 
bundle which will be sampled was stored dry continuously exposed to ambient air, in K-Area and later in L-Area. The condition of this fuel has been documented through video and still photographs as part of a fuel inspection program (see Figure 2). Due to the low power of the RU-1 research reactor, and an estimated cladding temperature of around $70^{\circ} \mathrm{C}$ during operation, this fuel is expected to have a thin oxide layer that is composed primarily of tri-hydrated aluminum oxide (gibbsite/bayerite). The oxide on the drystored fuel assemblies may have become dehydrated to an extent. The dry-stored RU-1 fuel plate, will be shipped to SRNL for analysis and testing. SEM and XRD analysis will be performed on oxyhydroxides harvested from cladding samples. SEM and XRD results will be compared to those of laboratory-grown samples to confirm the representativeness of laboratory generated specimens.

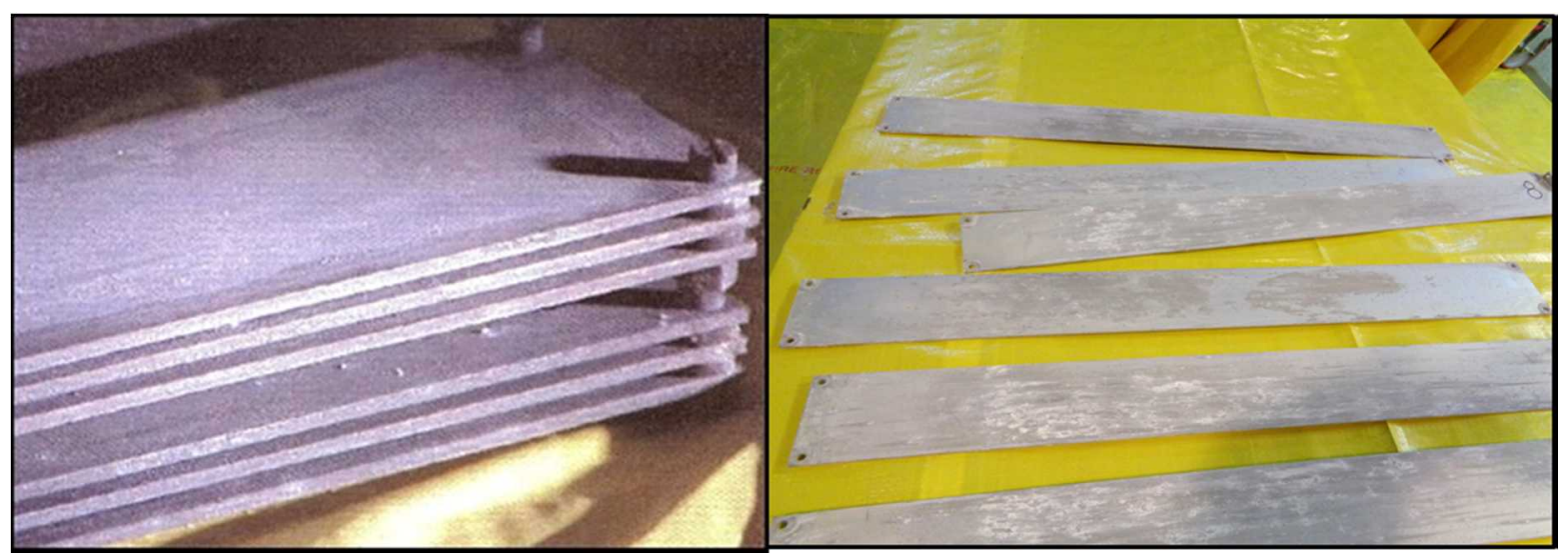

Figure 2. Plate fuel bundle (right) and debundled fuel plates (left) from Uruguay RU-1 Pool Reactor.

Validation activities using FY18 funding support the characterization and testing of oxides from a variety of L-Basin wet-stored aluminum scrap materials including a University of Missouri Research Reactor (MURR) tube end, Universal Sleeve Housing from L-Reactor (USH), as well as a cropped end from a Mark-16B fuel element.

The Universal Sleeve Housing (USH) is an aluminum (Al-6061) tube that was exposed in L-Reactor. These non-fuel tubes extend several feet into the reactor during operation and were typically exposed for a period of around 5 years, after which, they were discharged to the basin. The hot ends of the USHs where cropped and have been stored in buckets in L-Basin for more than 25-30 years. These non-fuel components are expected to have operated at temperatures nearly equivalent to the bulk moderator (heavy water) temperatures $\left(90-100^{\circ} \mathrm{C}\right)$. At these temperatures, it is anticipated that the oxide layer on the USHs would be boehmite, or a mixture of boehmite and gibbsite/bayerite.

MURR is a 10-MW, light-water cooled research reactor. There is currently a collection of tube ends from this fuel that is being stored in L-Basin in wet bucket storage. The cropped sections of the fuel assemblies include side-plates and end fittings (no fuel plates). It is estimated that the side plates of the MURR fuel assemblies were operated at temperatures greater than $80^{\circ} \mathrm{C}$. This operating temperature would promote the formation of boehmite, or a mixture of boehmite and gibbsite/bayerite, on the plate surface. The fuel croppings have been stored in L-Basin for more than 8 years.

The Mark 16B fuel assemblies were used as driver fuel enriched-depleted charges in P, K, and LReactors in the late 1970's through 1988. These fuel assemblies are aluminum clad enriched-uranium drives. The aluminum alloy used for the cladding of the fuel is Al-8001. Upon discharge of the fuel assemblies, each fuel assembly was cropped outside the fuel region and the cropped ends have been stored in buckets in L-Basin for more than 30 years. During exposure, the ends of the Mark 16B are estimated to have operated at temperatures exceeding $80^{\circ} \mathrm{C}$. At these operating temperatures, it is likely that the fuel tube ends would form an oxide layer of boehmite or a mixture of boehmite and gibbsite/bayerite. Because this material was exposed to heavy water in reactor, it is expected that the 
corrosion product may differ from oxides developed during light-water reactor service. Evaluation of both an USH and Mark16B cropped end will provide the evidence required to corroborate that expectation. The Mark 16B material has the additional challenge associated with the use of Al 8001 in its fabrication. It is not expected that the addition of nickel in the $\mathrm{Al} 8001$ will result in significantly different oxide composition, although it expected to have higher gamma dose rates commensurate with higher Co- 60 ingrowth.

\subsubsection{Shipment of Samples to INL for Experimental Testing}

Oxyhydroxides samples will be shipped to INL to accordance with procedures developed through post-immersion storage studies.

\section{REQUIREMENTS}

\subsection{General}

Task 6 will be required to grow, characterize, and validate oxyhydroxide surrogate samples for use in other studies within this ASNF program.

SRNL researchers and laboratory personnel supporting this task will:

- prepare a Task Technical and Quality Assurance Plan (TTQAP) [5]

- implement the Conduct of Research and Development process for all activities prior to the start of any laboratory work (per L1, 7.23) [6]

- utilize testing equipment (e.g., M\&TE, M\&SE) that is controlled in the SRNL calibration system

- characterize as-grown oxides, analyze experimental results and prepare technical reports as required

- record experimental activities and the analytical results in an electronic notebook (per L1, 7.30) [7]

$\circ$ provide task updates to INL collaborators as required.

\subsection{Measurement}

All measurements will be made using testing equipment (e.g., M\&TE, M\&SE) that is controlled in the SRNL calibration system. Experimental activities and analytical results will be recorded using an electronic notebook.

\section{ENVIRONMENT, SAFETY, AND HEALTH}

Task leaders and associated hands-on personnel will review the safety aspects of any experiments described in the SRNL TTQAP ${ }^{5}$ to determine their impact on the safety of personnel, equipment, and the facilities. Per SRNL Procedure Manual L1, Procedure 7.02, hazard analyses will be performed using the SRNL Hazards Analysis System (HAS) [8].

Each hazards analysis includes an assessment of the hazards followed by identification of the mitigation methods. The hazards review and mitigation methods are reviewed and approved by relevant subject matter experts for each hazard identified. Prior to performing work, personnel are required to review and sign the Hazards and Controls Summary. The hazard analysis also includes an assessment of the environmental controls for the task with review and approval by relevant subject matter experts. 


\section{QUALITY ASSURANCE AND DATA/RECORD MANAGEMENT}

A Task Technical and Quality Assurance Plan (TTQAP) for Aluminum Clad SNF Dry Storage Studies has been developed to support SRNL activities ${ }^{5}$. The Task QA Plan identifies the specific implementing procedures that will be used to control the task(s) described within the TTQAP. Project records will be managed and retained in accordance with the TTQAP.

\section{SCHEDULE}

The ASNF Dry Storage project was formally initiated in January of 2018 and will be completed by the end of 2019 Fiscal Year. Task 6 milestones are documented in Ref. 2 as well as provided in Table 1.

Table 1. Task 6 Schedule and Milestones.

\begin{tabular}{|l|r|}
\hline TASK 6 - Surrogate Sample Preparation and Validation \\
\hline Milestone 6.1: Growth/characterization of oxides on 1100 Alloy & $\mathbf{0 5 / 2 0 / 2 0 1 8}$ \\
\hline Milestone 6.2: Characterization of oxides on dry Uruguay fuel plate & $\mathbf{0 6 / 3 0 / 2 0 1 8}$ \\
\hline Milestone 6.3: Growth/characterization of oxides on 6061 Alloy & $\mathbf{0 8 / 2 0 / 2 0 1 8}$ \\
\hline Milestone 6.4: Growth/characterization of oxides on 5052 Alloy & $\mathbf{1 1 / 2 0 / 2 0 1 8}$ \\
\hline Milestone 6.5: Characterization of oxides on miscellaneous L-basin Al materials & $\mathbf{1 2 / 3 0 / 2 0 1 8}$ \\
\hline
\end{tabular}

\section{REFERENCES}

1. M.J. Connolly, Aluminum Clad Spent Nuclear Fuel Long Term Dry Storage Technical Issues Action Plan - Technical and Engineering Activities, INL/EXT-17-43908, 2017.

2. Aluminum Clad Spent Nuclear Fuel Long Term Dry Storage Technical Task Plan, INL, February 2018.

3. Aluminum Clad Spent Nuclear Fuel Long Term Dry Storage Project Execution Plan, PLN-5596, May 1, 2018.

4. M.D. Argyle, Aluminum Clad Spent Nuclear Fuel: Technical Considerations and Challenges for Extended (>50 Years) Dry Storage, DOE/ID RPT 1575, 2017.

5. Task Technical and Quality Assurance Plan for Aluminum Clad SNF Dry Storage Studies, SRNL-RPXXXX, May 2018.

6. Savannah River National Laboratory Procedure Manual, L1, 7.23: Conduct of Research and Development (R\&D)-Work Planning and Control, Rev.10.

7. Savannah River National Laboratory Procedure Manual, L1, 7.30: Electronic Laboratory Notebook and Logbook Experiments, Rev 2.

8. Savannah River National Laboratory Procedure Manual, L1, 7.02: Conduct of Research and Development (R\&D)-Hazards Analysis, Rev 10. 